\title{
Reactivity of Formic Acid on Calcium Carbonate Single Particle and Single Crystal Surfaces: Effect of Adsorbed Water
}

\author{
J. Baltrusaitis, ${ }^{*}$ C.R. Usher, ${ }^{*}, * *$ and V.H. Grassian* \\ * Department of Chemistry, University of Iowa, 305 CB, Iowa City, IA 52242 \\ ** Central Microscopy Research Facility, University of Iowa, 85 Eckstein Medical Research \\ Building, Iowa City, IA 52242
}

Formic and organic acids are ubiquitous in the atmosphere and are the most abundant organic acids present in urban areas. Calcium carbonate, an important mineral, plays a vital role in the neutralization of acidic gases in atmospheric aerosols [1]. As indoor air pollutants resulting from the decomposition of wood and cellulose acetate, formic and acetic acids are responsible for deterioration of carbonate building materials, as in museum objects (Byne's disease) [2].

The reactivity of formic acid $(\mathrm{HCOOH})$ under relatively dry $(\mathrm{RH}<15 \%)$ and humidified $(\mathrm{RH}>15 \%)$ conditions on calcium carbonate $\left(\mathrm{CaCO}_{3}\right)$ single particles and ( $\left.10-14\right)$ single crystal surfaces was investigated using Scanning Electron Microscopy (SEM) and Atomic Force Microscopy (AFM). Figure 1 shows formation of small islands and microcrystallites of calcium formate at the edges of $\mathrm{CaCO}_{3}$ single particle in the presence of $80 \% \mathrm{RH}$ water vapor. No microcrystallites were observed with SEM after exposure to the same concentration of formic acid in the presence of $10 \% \mathrm{RH}$ water vapor.

AFM images of freshly cleaved $\mathrm{CaCO}_{3}\left(\begin{array}{llll}1 & 0 & -1 & 4\end{array}\right)$ single crystal surface before and after exposure to $\mathrm{HCOOH}$ at saturation pressure are shown in Figure 2, a and b. Formation of crystallites $\sim 45 \mathrm{~nm}$ in height can be observed along step edges (Fig 2, b). Increase in crystal size, height, step edge roughening and enhancement in the crystallinity can be observed following exposure to water vapor at the saturation pressure for 10min (Fig 2, c) and for 24 hours (Fig 2, d). Thus, calcium formate changes from adsorbed to crystalline phase as the extent of the reaction increases with increased relative humidity.

It can be concluded, that at higher $\mathrm{RH}$ formic acid can react to greater extent with calcium carbonate. Adsorbed water on the surface of the carbonate particles participates in the greater reactivity of these by means of new reaction pathways due to dissociation of carbonic acid and formation of calcium formate islands and crystallites [1].

\section{References}

[1] H. A. Al-Hoshney, S. Carlos-Cuellar, J. Baltrusaitis and V.H. Grassian, Physical Chemistry Chemical Physics 7 (2005) 3587.

[2] T. Padfield, D. Erhardt and W. Hopwood, 'Trouble in Store', in N.S. Bromelle and G. Thomson, editors, 'Science and Technology in the Service of Conservation', preprints of the Washington D.C. Congress of the International Institute for Conservation, (1982), 24.

[3] This work was supported by the National Science Foundation (CHE-0503854) and the donors of the American Chemical Society (42820-AC5). Kenneth Moore and Central Research Microscopy Facility at the University of Iowa are gratefully acknowledged. 


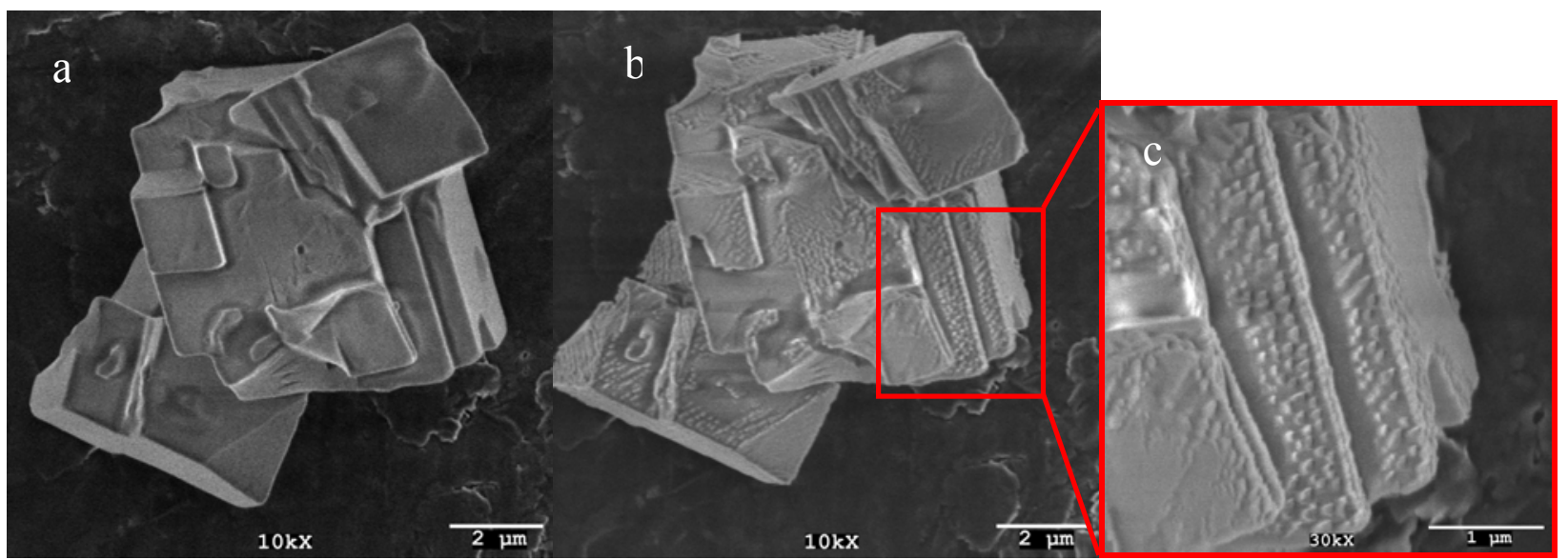

Fig. 1. A single $\mathrm{CaCO}_{3}$ particle before (a) and after (b) reaction with $\mathrm{HCOOH}$ in the presence of water vapor corresponding to $80 \%$ relative humidity (RH). Formed crystallites are shown in (c).

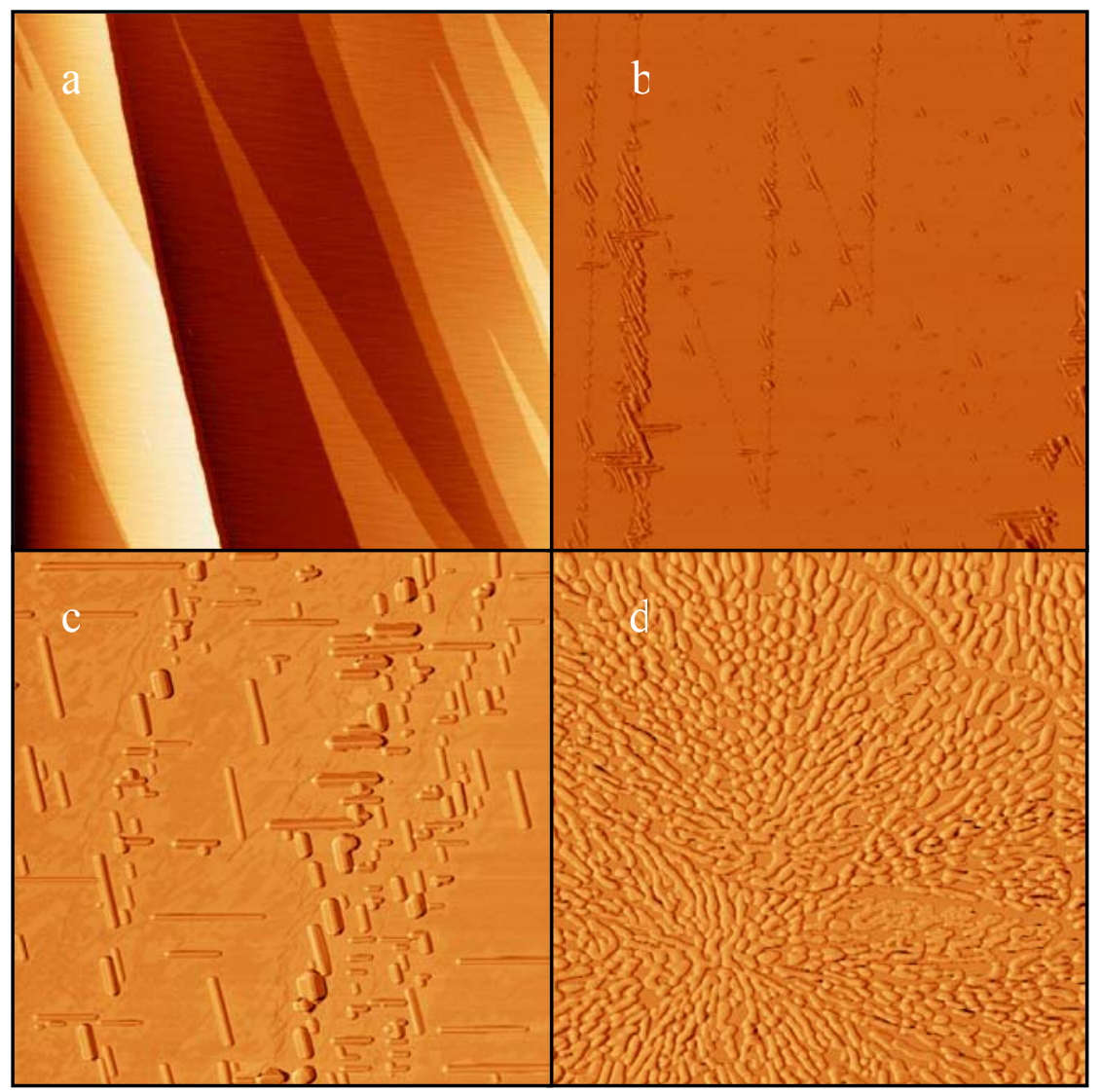

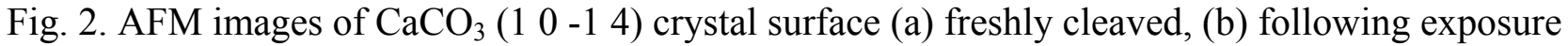
to $\mathrm{HCOOH}$ vapor at the saturation pressure for $10 \mathrm{~min}$., (c) following exposure to $\mathrm{HCOOH}$ vapor at the saturation pressure for $10 \mathrm{~min}$. then to $\mathrm{H}_{2} \mathrm{O}$ vapor at the saturation pressure for $10 \mathrm{~min}$., and (d) following exposure to $\mathrm{HCOOH}$ vapor at the saturation pressure for $10 \mathrm{~min}$. and to $\mathrm{H}_{2} \mathrm{O}$ vapor at the saturation pressure for 24 hours. All images are 5 x $5 \mu \mathrm{m}$ size. 